\title{
Ovarian Borderline Tumor and Fertility-Sparing Surgery
}

\author{
André Reis Correia, MD, Vanessa Gomes Olival, MD, Carla Freire Leitão, MD, and Fazila Mahomed, MD
}

\begin{abstract}
Background: Ovarian borderline tumors (OBTs) are frequently diagnosed in women of reproductive age. There is no consensus about their management, and it sometimes represents a dilemma about what should be done: fertilitysparing surgery or a hysterectomy with salpingo-oophorectomy? Case: A 32-year-old nulligravida, diagnosed with a right ovarian borderline tumor is presented. She underwent pelvic washings, right salpingo-oophorectomy, appendectomy, and omental and peritoneal biopsies (laparotomic approach). Macroscopically, the left ovary was normal and subsequent exploration for staging was also normal, including the lymph nodes. Intraoperatively, frozen section examination was unclear, suggesting an OBT. Results: The final histopathologic diagnosis was ovarian borderline tumor, stage IIC (International Federation of Gynecology and Obstetrics [FIGO] staging). The patient expressed a desire to preserve her fertility. Thirty-six months postsurgery, she became pregnant spontaneously and delivered a healthy newborn at term. Conclusions: Conservative surgery can be performed in young patients treated for an OBT, provided they are closely followed up and that this surgery is performed after careful consideration and informed consent. It is, however, controversial with respect to performing hysterectomy and salpingo-oopherectomy upon the patient's completion of childbearing. (J GYNECOL SURG 29:292)
\end{abstract}

\section{Introduction}

$\mathbf{O}$ VARIAN BORDERLINE TUMORS (OBTs) ARE frequently diagnosed in women of reproductive age. There is no consensus regarding their management, and it sometimes represents a dilemma: fertility-sparing surgery or a hysterectomy with salpingo-oophorectomy?

\section{Case}

A healthy, 32-year-old nulligravida required a gynecologic assessment for amenorrhea. She was diagnosed with a pelvic retro-uterine mass, $112 \times 106 \mathrm{~mm}$, with an apparent right adnexal origin. The patient's CA-125 levels were elevated $(324 \mathrm{U} / \mathrm{mL})$ and diagnostic laparoscopy confirmed an adnexal tumor with a suspicious ultrasound and macroscopic appearance. The patient was subjected to pelvic washings, right salpingo-oophorectomy, appendectomy, and omental and peritoneal biopsies. Macroscopically, the left ovary appeared normal upon exploration for staging, and the lymph nodes were normal in size. The results of the intraoperative frozen section analysis were unclear, but suggested an OBT.

The final histopathologic diagnosis was serous borderline ovarian tumor with foci of microinvasion and the presence of malignant cells in pelvic washings, and peritoneal invasive implants at the pouch of Douglas (stage IIC, International Federation of Gynecology and Obstetrics [FIGO]).

\section{Results}

The patient expressed a desire to preserve her fertility. Based on a multidisciplinary decision, she was subjected to six cycles of chemotherapy and a close follow-up, in which she was asymptomatic and without any signs of recurrence.

Thirty-six months postsurgery, she became pregnant spontaneously. She had an uneventful pregnancy and a eutocic delivery at term. Fifty months later, she was clinically well, and not planning further pregnancies. A decision was then made to perform a hysterectomy and a contralateral salpingo-oopherectomy.

\section{Discussion}

OBTs are a heterogeneous group of tumors, representing $15 \%$ of all epithelial ovarian tumors. ${ }^{1}$ They tend to be diagnosed early compared with other malignant tumors, and frequently affect women in reproductive age. Preoperatively, borderline tumors are often presumed to be either benign or malignant ovarian masses; OBTs and stage I epithelial ovarian carcinoma (EOC) may have a similar ultrasonographic patterns. ${ }^{2}$ CA-125 is often measured as a second stage test to estimate the likelihood of malignancy in adnexal lesions detected by ultrasound examination: median serum CA-125 levels are higher in patients with OBT than in healthy controls, and lower than in those with invasive ovarian

Department of Gynaecology/Obstetrics, Hospital D. Estefânia, Centro Hospitalar de Lisboa Central, Lisbon, Portugal. 
cancers. ${ }^{3}$ According Zacharakis et al., ${ }^{4}$ preoperative values of CA-125 > 100 international units (IU) $/ \mathrm{mL}$ proved to be an independent discriminator between OBTs and stage I EOC: women with CA-125 > $100 \mathrm{IU} / \mathrm{mL}$ had an almost three times greater likelihood of belonging in the EOC group. Misinterpreting $\mathrm{OBT}$ as invasive ovarian cancer may result in serious and unnecessary procedures and morbidity (such as hysterectomy and lymphadenectomy).

In this case, because the tumor appeared suspicious upon macroscopic examination, a right salpingo-oophorectomy with intraoperative histopathologic examination was performed, which suggested an OBT. Previous studies show that these tumors can be correctly diagnosed in $58 \%-86 \%$ of cases by intraoperative frozen section analysis, depending upon the experience of the pathologist. ${ }^{1}$

As the patient was nulligravid and the tumor was at an early stage (as in the majority of reported cases), fertility-preserving surgery was performed. Final diagnosis confirmed a stage IIC (FIGO) serous OBT. The patient decided against undergoing a hysterectomy and a contralateral salpingo-oopherectomy, despite being informed of the associated risks. Conservative surgery can be performed in younger patients treated for OBTs, provided that they are carefully followed-up. ${ }^{15,6}$ The overall risk of recurrence after conservative surgery ranges from $7 \%$ to $30 \%{ }^{7}$ The postoperative management protocol is far from clear: most clinicians agree that there are no advantages to chemotherapy for stage I tumors. However, with respect to stage II-IV tumors, there is no consensus on the benefits of chemotherapy and such benefits have never been proven. ${ }^{1}$ Many investigators believe that factors that may bring about a poorer prognosis are the presence of invasive peritoneal implants, ${ }^{1,5}$ an older age at diagnosis, elevated preoperative CA-125 levels, micropapillary histology, ${ }^{5}$ and foci of microinvasion. ${ }^{8}$ According to a study by Gershenson et al., ${ }^{9}$ serous OBTs with peritoneal implants have a relapse rate of $31 \%-45 \%$, with a median time from diagnosis to recurrence of 24 months. In cases with a higher risk of persistence/recurrence, patients should be given postoperative chemotherapy, and followed closely thereafter. ${ }^{5}$

Given the high risk factors and poor prognosis of this patient, she received adjuvant therapy. She became spontaneously pregnant after trying to conceive for $<1$ year. Previous studies have shown that pregnancy itself does not affect the prognosis of the disease. ${ }^{10,11}$ A review identified 254 pregnancies in 206 patients; the investigators calculated the overall pregnancy rate at $48 \%$, based on the published numbers of women trying to conceive. ${ }^{12}$ Another study reported $60 \%-88 \%$ of spontaneous pregnancy rates following fertility saving surgery, therefore not justifying overtreatment for fertility. ${ }^{13}$

Fifty months postsurgery, the patient was clinically well and not planning further pregnancies; therefore, she decided to undergo a hysterectomy and a contralateral salpingooopherectomy. This is a controversial topic, and the guidelines from the National Comprehensive Cancer Network $(\mathrm{NCCN})$ argue about this approach (category $2 \mathrm{~B}){ }^{14}$

\section{Conclusions}

Combining tumor marker measurement and ultrasonography might increase the accuracy of diagnosis, in order to choose the hospital (with experienced gynecologic pathologists) and determine which type of surgery is appropriate.
In conclusion, a fertility-sparing approach in special cases should be decided only after thorough discussion and informed consent by the patient, and by carefully balancing the risks and benefits. Gynecologic oncologists should be fully aware of their double role in treating the malignant disease as well as in providing oncofertility care to young patients.

\section{Disclosure Statement}

No competing financial interests exist.

\section{References}

1. Green AE. Borderline Ovarian Cancer: Borderline Tumor Overview. Online document at: www.emedicine.medscape.com/ Accessed August 18, 2012.

2. Lee EJ, Kim SH, Kim YH, Lee HJ. Is CA-125 an additional help to radiologic findings for differentiation borderline ovarian tumor from stage I carcinoma? Acta Radiol 2011;52:458.

3. Lenhard MS, Nehering S, Nagel D, et al. Predictive value of CA-125 and CA 72-4 in ovarian borderline tumors. Clin Chem Lab Med 2009;45:537.

4. Zacharakis D, Thomakos N, Biliatis I, et al. Ultrasonographic markers and preoperative between CA-125 to distinguish between borderline ovarian tumors and stage I ovarian cancer Acta Obstet Gynecol Scand 2013;92:285.

5. Chen L-M, Berek JS. Ovarian tumor of low malignant potential. Online document at: www.uptodate.com/ Accessed August 18, 2012.

6. Koutlaki N, Dimitraki M, Zervoudis S, et al. Conservative surgery for borderline ovarian tumors-emphasis on fertility preservation: A review. Chirurgia (Bucur) 2011;106:715.

7. Boran N, Cil AP, Tulunay G, Ozturkoglu E, Koc S, Bulbul D. Fertility and recurrence results of conservative surgery for borderline ovarian tumors. Gynecol Oncol 2005;97:845.

8. Ferrero A, Strada I, Di Marcoberardino B, et al. Clinical significance of microinvasion in borderline ovarian tumors and its impact on surgical management. Int J Gynecol Cancer 2012;22:1158.

9. Gershenson DM, Silva EG, Levy L, Burke TW, Wolf JK, Tornos C. Ovarian serous borderline tumors with invasive peritoneal implants. Cancer 1998;82:1096.

10. Nam JH. Borderline ovarian tumors and fertility. Curr Opin Obstet Gynecol 2010;22:227.

11. Morice P, Camatte S, El Hassan J, Pautier P, Duvillard P, Castaigne D. Clinical outcomes and fertility after conservative treatment of ovarian borderline tumors. Fertil Steril 2001;75:92.

12. Swanton A, Bankhead CR, Kehoe S. Pregnancy rates after conservative treatment for borderline ovarian tumours: a systematic review. Eur J Obstet Gynecol Reprod Biol 2007;135:3.

13. Ayhan A, Celik H, Taskiran C, Bozdag G, Aksu T. Oncologic and reproductive outcome after fertility-saving surgery in ovarian cancer. Eur J Gynaecol Oncol 2003;24:223.

14. National Comprehensive Cancer Network (NCCN) guidelines. Epithelial Ovarian Cancer/Fallopian Tube Cancer/ Primary Peritoneal Cancer. Online document at: www.ncen .org/ Accessed August 18, 2012.

Address correspondence to: André Reis Correia, $M D$ Rua José Maria Nicolau No. 4 5o.A 1500-374 Lisbon Portugal

E-mail: andre_reis@portugalmail.pt 
Copyright of Journal of Gynecologic Surgery is the property of Mary Ann Liebert, Inc. and its content may not be copied or emailed to multiple sites or posted to a listserv without the copyright holder's express written permission. However, users may print, download, or email articles for individual use. 